\title{
An interview study of the experiences of middle-aged women living with constipation
}

\author{
Kristina Lämås *, Eva Anundsson, Ann-Christine Stare, Catrine Jacobsson \\ Department of Nursing, Umeå University, Sweden
}

Received: September 23, 2014

Accepted: November 25, 2014 Online Published: December 10, 2014

DOI: $10.5430 /$ cns.v3n2p1

URL: http://dx.doi.org/10.5430/cns.v3n2p1

\begin{abstract}
Introduction: Constipation is relatively common, especially among women, but little is known about the experience of living with constipation. Aim: To explore the experiences of middle-aged women living with constipation. Design: A qualitative, descriptive design.

Method: Six women in middle age (50-64 years) with constipation were interviewed in 2005-2007 about their experiences of living with constipation. The interviews were transcribed and the data were analyzed with qualitative content analysis.

Result: The women described being constipated as being alone in an excruciating condition where life alternated between feeling tormented and feeling released, and this condition evoked feelings of stress and anxiety. Difficulties in discussing constipation and a lack of support meant that they were alone in their struggle and they felt humiliated when seeking healthcare services. Life was seen as an endless struggle between being mastered by the bowel and mastering the bowel.

Conclusion: Even though data has been collected more than five years ago, the experiences described by the women are deemed to be highly valid for today. It is essential that fundamental needs like elimination are satisfied, but constipation problems seems to be neglected in the healthcare system. It is important, therefore, that patients' complaints are taken seriously.
\end{abstract}

Key Words: Constipation, Experience, Qualitative research, Women

\section{Introduction}

Constipation is a common condition, especially among women, that brings a lot of discomfort and is related to low quality of life. ${ }^{[1]}$ Despite that, little is known about the experience of living with constipation and how it affects an individual's life. Expanded knowledge in this area is critical in order for healthcare professionals to give high-quality care to individuals with this condition.

In Sweden, about $20 \%$ of all women and $8 \%$ of all men re- port having constipation, and these numbers are assumed to be in line with those in other parts of the Western world. ${ }^{[2]}$ The prevalence increases with age, ${ }^{[3-7]}$ but one study found that younger and middle-aged persons reported significantly lower bowel movement frequency than did older persons. ${ }^{[7]}$ The normal variation in bowel movement frequency is wide, ${ }^{[8]}$ and the number of bowel movements is inadequate as a single measure of constipation. The Rome criteria have been used to diagnose constipation and the number of bowel movements is only one of several criteria. ${ }^{[9]}$ Other criteria in

*Correspondence: Kristina Lämås; Email: kristina.lamas@.umu.se; Address: Department of Nursing, Umeå University, 90187 Umeå, Sweden. 
Rome II, which was used in this study, are that in one fourth of the defecations: 1) experiencing straining, 2) lumpy and hard stools, 3) sensations of incomplete evacuation, 4) sensations of rectal obstruction/blockage, 5) manual manoeuvres to facilitate defecation, and 6) less than three defecations per week. Constipation is diagnosed if two or more of the conditions had occur for 12 weeks during the previous 12 months.

Constipation appears to be more common among women $;{ }^{[4,10,11]}$ in one Australian study, ${ }^{[12]}$ the prevalence of constipation was $24 \%$ in middle-aged women. However, the higher prevalence in women has been questioned by McCrea et al. ${ }^{[11]}$ that suggested that the higher prevalence in women could be due to women being more prone to report symptoms and to participate in research. Another explanation for higher prevalence among women could be pelvic floor dysfunction which is found to be more common among women. ${ }^{[13]}$ The prevalence of pelvic floor dysfunction and constipation increases in relation to delivery and number of children after adjusting for age. ${ }^{[13,14]}$ Childbirth can be one factor that contributes to the difference in constipation rates among men and women.

Women who live with persistent constipation have been found to have a lower quality of life and higher levels of self-reported depression. ${ }^{[15]}$ In general, little is known about the experience of living with constipation but there a few studies reporting about living with the condition. In our recent study, ${ }^{[16]}$ one women described her relationship to her bowel almost as a war: she was fighting and almost punishing the bowel with laxatives, which resulted in a sore bowel, but this was the only way she knew to handle the situation. Another study ${ }^{[17]}$ explored older persons' (> 65 years of age) experiences of being constipated, in which they reported unpleasant feelings of bloating, cramps and nausea that affected their health and well-being. They related being preoccupied with their bowels and needing to have immediate access to a toilet, which hampered social activities. Feelings of despair, hopelessness and resignation were experienced, together with feelings of isolation, anxiety and loneliness. ${ }^{[17]}$ Persons with cancer (48-80 years) have described their experience of being constipated as being affected physically, mentally, socially and existentially. Constipation has had a significant impact on their lives and has been a primary focus in their daily living. ${ }^{[18]}$

Constipation is a common condition, but even if it is more common in the elderly, people of other ages also struggle with the condition. The knowledge about the experiences of middle-age women living with constipation is lacking and need to be studied further.

\section{Aim}

The aim of the study was to describe the experiences of middle-aged women living with constipation.

\section{Method}

\subsection{Design}

This study is a part of a larger project aiming to explore the effects of abdominal massage. It is a qualitative, descriptive study based on individual interviews. Qualitative content analysis was used to derive the experiences of middle-aged women living with constipation. The study took place in Sweden from 2005 to 2007.

\subsection{Participants}

The participants in the larger project $(n=60)$ were recruited via advertisements in local newspapers $(n=55)$, care centres $(n=0)$ and nursing homes $(n=5)$. The researchers had no prior relationship with the participants. The inclusion criteria were to be an adult, to be able to speak and understand Swedish, and to be constipated according to the Rome II criteria as described above. ${ }^{[19]}$

In the larger project, a convenience sample of 20 participants was interviewed one time about their experiences of living with constipation. Of the 20 participants, all women in middle age (50-64 years; $n=6)$ constituted the participants in this study. The decision was based on the fact that to our knowledge no study has focus the middle age women's experiences. One can assume that being in the middle age may bring different life circumstances compared to women in old age. All six participants lived in their own home. Three of the women lived alone and three lived with their spouses; in addition, five of the six participants worked, and four had self-reported chronic pain. Although, the participants reported to had been constipated for several years, most of them could not specify when the problem begun. Some reported being constipated from childhood, other reported at least 10 years of problem. Since all participants had voluntary applied to the intervention study looking for relief of constipation, it is reasonable to assume that their problem with constipation was severe.

\subsection{Data collection}

In the interview with the first participant in the larger project, the topic was found to be difficult to talk about because of its private nature. To increase the possibility of obtaining a richer interview with the other participants, the interviewer (KL, the first author) and each interviewee therefore met two to three times before the interview. The interviews were face-to-face and semi-structured using an interview guide focused on the experience of being constipated, the ways that constipation affected daily life and well-being, and the experience of using laxatives. The interviews started with an open-ended question, "Can you tell me about how your bowel works now?" During each interview, the interviewer attempted to stay open and sensitive to the informant's narrative and followed up with exploratory questions. 
Regarding the current study, three interviews were conducted in the informant's home and three were conducted at the informant's workplace; no other persons were present during the interviews. The interviews lasted from $25 \mathrm{~min}-$ utes to 1 hour and 20 minutes, and were tape recorded and transcribed verbatim.

\subsection{Ethical considerations}

The informants gave their informed consent after receiving both oral and written information about the study. They were assured confidentiality and anonymity in the presentation of the results. The study was approved by the Ethics Committee at the Medical Faculty at Umea Univserity.

\subsection{Data analysis}

The text was subjected to qualitative content analysis. ${ }^{[20,21]}$ This method aims to systematically describe similarities within and differences between sections of text. We performed an inductive analysis of manifest and latent content. ${ }^{[20]}$ Specifically, two authors (EA and AS) performed the analysis in discussion with the other two authors (KL and $\mathbf{C J}$ ). First, the interviews were read several times to gain an overall understanding of what the informants were talking about. In the next step, the text was divided into meaning units, each one representing a single unit of content. Then the meaning units were condensed and labelled with descriptive codes close to the text. The codes were abstracted and sorted into categories according to differences and similarities. Finally, the categories were abstracted and sorted into two themes and five subthemes representing an interpretation of the underlying meaning.

Two authors (EA and AS) divided the text into meaning units and labelled those with codes, which all four authors then compared and discussed until consensus was reached, in order to formulate the most suitable codes. Throughout the process, the analysis moved back and forth between codes, categories, themes, subthemes and the text. All steps and interpretations in the process were reflected upon and discussed in the research group, to ensure stringency and trustworthiness in the analysis. Representative quotes from the text are presented in the Findings section, to verify our interpretations and allow the reader to validate the findings. The names following the representative quotes have been assigned by the authors to maintain the interviewees' anonymity.

\section{Result}

The women in the current study reported that being constipated meant being alone in an excruciating condition, where life fluctuated between feeling tormented and feeling released depending on the condition of the bowel, and that this experience evoked feelings of stress and anxiety. Due to the intimate nature of the condition, which made it difficult to talk about, and the lack of support from the healthcare system, the women felt that they were alone in their struggle. They also expressed feeling humiliated when their desire for support was ignored or turned into a joke. Life for these women was an endless battle, where they expressed feelings of being mastered by the bowel and at the same time struggling to master the bowel. These themes and subthemes are discussed in the rest of the Findings section.

\subsection{Being alone in an excruciating condition}

The theme "being alone in an excruciating condition" describes how constipation affects life in different ways, both physically and mentally. The situation is worsened by the fact that constipation and problems with defecation seem to be taboo subjects and to be neglected by the healthcare system, and this situation evokes feelings of loneliness and humiliation.

The theme has three subthemes: "tossed between feeling tormented and feeling released", "living with constant stress and anxiety" and "feeling alone and humiliated".

Tossed between feeling tormented and feeling released. To live with constipation seems to imply alternating between feeling tormented and feeling released. The interviewees described how they felt "out of order" because constipation affects the whole body in different ways. They said that a full bowel results in a feeling of discomfort that one wants to get rid of. Being constipated means having strenuous defecations: "Well, you have to push with all you have ... it's sweaty work until you get rid of that lump" (Eve). If a long time had passed since evacuation, the bowel could become upset and produce other forms of discomfort: "It is tough from the beginning; it is flowing, it bubbles and simmers, you have to hurry up" (Nora). The defecations were described as "attacks" that the informants feared, and which they described as being very painful and excruciating, stating that sometimes the anus would rupture and bleed. The struggle to defecate put the whole body out of balance, and one informant said that she felt like she was going to faint: "I sit there and feel how the bowels are working. I maybe defecate bit by bit, and then I feel like my whole body becomes devastated. I start to sweat and just become exhausted; I feel like I am going to faint. I have a bucket, I vomit, I lay down on the bathroom floor, the sweat is flowing" (Annie).

The interviewees described the body as being affected in other ways. One interviewee reported having headaches that were similar to a migraine: "When I have constipation and have this headache, it is almost like a migraine. This is not funny; I have to take pills because you cannot function well if you have a headache" (Beth). The interviewees also said that the bladder was affected, and sometimes it was difficult to urinate before the bowel was empty. The bowel could be so full that the bladder became irritated, and this meant that 
they would have to go to the toilet several times during the night and so their sleep was disturbed. The informants said that they experienced having problems with urine incontinency when they drank too much fluid, and so they avoided doing so.

Participants described a feeling of release when they had bowel movements, and that these were the best of days, just to feel the release before everything started over again: "It feels like a release, it feels like I lost several pounds ... then you feel fine for a few of days, but then it starts filling up again. For three or four days I feel fine" (Jenny).

Living with constant stress and anxiety. In the interviews, it appeared that informants experienced stress and anxiety in different ways depending on their constipation. They described feeling stressed if bowel movements did not occur, because that meant the bowel movements would be more strenuous and painful later on. The need to go to the bathroom could be acute, which also gave rise to a feeling of stress, especially when at work or in other places than home. It was easier when they were at home, because then the bowel movement could be allowed to take its time. Problems with gas and bally-ache also caused stressful moments because of experienced loss of control. In public situations at work one informant described fear about how the bowel would act; "I can be quite nervous when meeting famous persons, and I talk to the bowel 'be quite, do not embarrass me', I cannot hide anywhere" (Nora).

The informants also described anxiety in relation to laxatives. There was some uncertainty about whether laxatives could destroy the gut and lead to addiction, and this uncertainty led the informants to avoid using laxatives. They express anxiety about that the laxatives would lose its effects if been taken too often: "I do not want to take laxative ... because I believe that I than have to take more and more" (Nora). They then feared to be without aid. One interviewee also described anxiety when she needed to go the bathroom after taking a laxative, because the subsequent defecation could be quite painful: "Then it feels all right, but you dread when the bowel movement will start because the stool is hard" (Jenny). Not taking laxatives also seemed to arouse anxiety, because the informants often worried that if a stool was left too long in the intestine, it could cause other diseases such as cancer.

Feeling alone and humiliated. The interviewees described having constipation as being alone, since it was difficult to share experiences with others when the subject is surrounded by taboo and is highly private. Because it is highly private, this also makes it difficult to talk to healthcare personnel about the need for help with constipation. One interviewee described gathering the courage to seek help, only to feel that she was treated badly and not taken seriously: "I feel that I have just been neglected; they (healthcare workers) have almost made fun of me. My stomach was so swollen that I could not button my pants and I had such pain. The physician thought that I could wear suspenders instead, so I could hold up my pants. I became so angry ... I cried when I went home and said to myself, 'Never again. I shall never again trouble them ... ever'”(Eve).

Being constipated seemed to imply being humiliated, and another informant reported on a wish to be seen as a person: "I do not want to be seen as a constipated person" (Karla). The fact that the subject is taboo also brought about feelings of humiliation when the smell and noise related to evacuation became apparent. Stools were described as being more foul smelling when the individual is constipated. This situation makes it embarrassing to have to go to the bathroom in others' homes or at work, and so was avoided if possible: "You look for a bathroom because the smell ... you know, the smell is worse when you haven't emptied the bowel for a while. I use the common bathroom and not the one for the staff ... so no one will know it's me" (Nora).

\subsection{Being in a never-ending battle}

The theme of "being in a never-ending battle" suggests that constipation puts numerous obstacles in the way of living life in a manner that many others take for granted. Being constipated brings about feelings of being mastered by the bowel and being forced to adjust one's activities according to the needs of the bowel. Trying to master the bowel demands significant time and planning, and means that one must always be on the lookout for something that could diminish the problem. Although this effort becomes a habit and part of life, the women described it as tiresome but necessary to endure.

The theme has the two subthemes of "feeling mastered by the bowel" and "struggling to master the bowel".

Feeling mastered by the bowel. The women reported that their constipation caused them to avoid activities in public areas, such as shopping and going to the cinema, if possible. One informant said that it was important to have a bathroom close by, because she must have the ability to go immediately upon feeling the need: "I have to go immediately when I feel the signals. I can't wait for someone else (who is) in the bathroom" (Beth). The need to have immediately access to a bathroom implies that in general the women may be afraid of being in public areas where bathrooms can be far away and where they may have to stand in line before they can enter the bathroom. The pain in the stomach was also described as sometimes being so bad that it was necessary to lie down on the floor, even in a public bathroom, until the pain ceased.

To visit friends was also described as being difficult, and the women said that they often stayed home, or if attending a dinner party, they would have to leave the party because of the need to defecate. It would be embarrassing to use someone else's bathroom, especially if it should take a long time 
and others might wonder why, or maybe there would be an unpleasant odour in the bathroom afterwards. To visit other people's bathrooms was experienced as too stressful and it was easier to go home. It also takes time to take care of the gut, and sometimes the women have to go to the bathroom several times before the bowel is empty. Altogether, these issues and the uncertainty of their intensity and frequency resulted in a feeling of being mastered by the bowel and unable to take part in activities outside home.

The informants also said that constipation demands that they make plans to take care of the bowel. If they are away for a weekend, laxatives have to be taken the day before leaving or they have to wait until returning home: "If I know that we will be away during the weekend, then I take it when I am free from work, on Friday for example, when I am alone at home" (Jenny). The gut can also be sensitive to changes in routines which makes it difficult to travel: "Then we had been gone for 14 days and nothing (no bowel movement) had happened" (Jenny).

Being constipated also made it difficult to handle a job. The work had to be flexible so that it could be adjusted to the bowel when necessary: "It works at my job because we are two employees and, if necessary, I can go away and lay down for a minute" (Eve). The women also said that diet could be problematic and they could not eat anything that they longed for or were invited to eat. It was necessary to eat the "correct" food; otherwise, the bowel would become constipated.

Struggling to master the bowel. To be able to have a bearable life, the participants said that they had to adjust their life to their bowel condition: "I have to adapt my life after my bowel" (Beth). They described that they had to face the truth, this life is the life they had. The adaption was an integrated part of their life situation and thereby, no choice was available, this was life; "it works, it must work, I do not know anything else, I use to say when I have had a bowel movement; oh, is it like this it should be? ... You do not know what life could have been without constipation ... it is probably lucky that we works like that, otherwise life would be unbearable" (Jenny). To adjust to the bowel became a habit and part of life. They described how they experimented with diet and fluid; "I wanted to handle this without laxatives, I tried with plums and vegetables and to drink more" (Jenny). The informants also described experimenting with different kind of laxatives, beside troublesome side effects there was described to be difficult to find anything that had permanent effect; "it can be effective sometimes but there is nothing that remains effective beside stimulant laxatives" (Nora). They also talked about being tired of always searching for strategies to find solutions to make bowel movements more regular and to eat correctly, which sometimes resulted in bowel movements: "One has to try to eat fibre and such foods, and perhaps drink more, but it is difficult to be perfect" (Annie). The interviewees also reported that it was

Published by Sciedu Press important to be physically active, and that it was even more important to be observant of the bowel and be extra careful when travelling; "you have always to think about ... not to forget to bring laxatives, and also bring enemas, this is just the way it is, but it would be nice if it could work without ... But it doesn't" (Nora). It seemed to be necessary for the women to not change their habits, because doing so often resulted in more problems with the bowel. They had to adjust their lives to maintain a bearable situation, and it was a never-ending struggle to master their bowels.

\section{Discussion}

\subsection{Discussion of the findings}

The women in this study described the experience of living with constipation as being alone with an excruciating condition that burdened them with both physical and psychological stresses. The physical ailments included feeling sick, having cramps and bloating, and enduring strenuous and painful defecations, and these ailments have been described in previous studies. ${ }^{[17,22]}$ The women did not describe constipation as a reminder of death, as was found by ${ }^{[18]}$ Friedrichsen and Erichsen, ${ }^{[18]}$ but constipation seemed to affect their lives in a comprehensive manner. It seems reasonable to compare our findings with those of Dennison et al., ${ }^{[23]}$ who indicated that people with constipation have a low quality of life in relation to their health.

The middle-aged women in this study described their constipation in many ways that can also be found in the narratives of other people with constipation, regardless of age or sex. However, the subtheme "feeling mastered by the bowel" revealed some complications in everyday life that can be specific to this group. These complications do not depend on age or sex per se but are complications related to being of working age. It was important for the women in this study to have a flexible job that allowed them to leave for a while if necessary when experiencing pain or the urge to visit the bathroom. This requirement for flexibility affects the ability to freely choose work based on interests or other favourable circumstances. To live with constipation while being employed also means adjusting the time when laxatives are taken. Laxatives had to be taken on days free from work which means that those days free of work have to be spent taking care of the bowel.

A further complicating factor when working is that constipation is a taboo subject, and this taboo implies that the condition is hidden. It is difficult to talk about and, therefore, may lead to a lack of understanding from colleagues when visits to the bathroom are sudden and take a long time. It could also imply avoiding the use of the staff bathroom due to possible odours and instead going to a bathroom away from the worksite.

Similar issues have also been seen in relation to other 
bowel-related dysfunctions such as irritable bowel syndrome (IBS). Ronnevig et al. ${ }^{[24]}$ found that the taboo surrounding such intimate problems poses a threat to dignity, and the participants in this study tried to maintain their dignity by being discreet, not talking about their condition and adjusting their lives to the circumstances surrounding their condition. This taboo has historical roots, and the primary focus in industrialised society has been on consciousness and logical/rational abilities, while physical phenomena have been associated with disgust and shame. ${ }^{[25]}$ Disciplining the body has been an important goal in the process of civilisation, which has led to bodily functions becoming a taboo subject. First, the body was privatised and then it was made so intimate as to become an almost unmentionable part of the human being. When subjects surrounded by taboo become visible, people respond with shame and are filled with discomfort. ${ }^{[25]}$

Being constipated was described as a condition in which physical suffering was combined with psychological suffering such as shame and humiliation. The participants in our study told of difficulties in discussing their condition with healthcare personnel. It is important to note that these problems are probably not related to age or sex, but are instead related to the condition itself. One source of these issues seems to be the matter of taboo, since constipation is an intimate condition that may be difficult to draw attention to and can require significant courage to seek help for. Another source of the difficulties described by the women seems to be healthcare personnel's poor attitude and the fact that they tend to view constipation as a minor problem. The participants in our study considered that their condition was ignored and that their complaints were not taken seriously. Constipation is, in fact, often only a minor problem, but in severe cases it can cause extreme distress in afflicted individuals and can have a significant negative impact on their daily lives.

The experience of not been taken seriously when contacting healthcare personnel to seek help for constipation has been reported by Friedrichsen and Erichsen. ${ }^{[18]}$ It has been hypothesised that constipation has low status and that nurses, and probably also other professional groups, are unwilling to deal with the subject. ${ }^{[26]}$ It has also been found that constipation is often regarded as a benign condition, which might also lead to the condition not being of high priority among healthcare workers. ${ }^{[1]}$ However, constipation is an important subject from both the patient's perspective (in terms of decreased quality of life) and the healthcare perspective (in terms of prolonged hospital stays and increased healthcare costs) and must be taken seriously. When meeting patients, it is wise to remember that it can be embarrassing for the patients to talk about their condition and that it demands courage to seek help for the condition. It is crucial to take time to listen to patients' experiences with respect and understanding.
The women in our study had suffered from constipation for several years. Even if living with constipation was described as tiresome, it had become a habit and a part of life. This finding is in line with what Ronnevig et al. ${ }^{[24]}$ found in relation to IBS. Even though constipation was described as a part of life in our study, there was also a strong wish to be rid of the problem and to be "normal".

\subsection{Methodological discussion}

Despite the small number of participants in this study, the interviews were rich and resulted in a large amount of material that illuminated the participants' experiences of living with constipation. Because trustworthiness in a qualitative study is gained more by richness in the data than by sample size, ${ }^{[27,28]}$ six participants can be considered a sufficient sample.

Because the interviewees were participating in a study on constipation treatment, it is probable that they were individuals who have had difficulties in finding effective treatments and they might have more severe problems. This factor probably had an impact on the narrative in this study and could explain why predominantly difficult experiences were reported on in the text. Our results are based on women's stories, and it is unknown if the findings are unique to women, as there is also a lack of research on men with constipation.

During the analysis, the authors reflected on and discussed the interpretations until consensus was reached. However, a text is never considered to have only one single meaning, and thus the narrative presented in the current work must be seen as only one of many possible interpretations. ${ }^{[21]}$ There is a lack of knowledge in the area of constipation and it needs further exploration; in addition, studies with larger and more diverse samples are suggested.

The interview data were collected as part of a larger project with substantial data collection and extensive data analysis. Even though data has been collected more than five years ago, the experiences described by the women are deemed to be highly valid for today. It is reasonable to assume that the physiological impact of constipation is rather stable over time. However, the psychological impact could possibly vary according to attitudes in the society. The highly private nature of constipation described in the interviews was found to have great impact on the experiences, the highly private nature has not likely been changed during the years since the interviews where done.

\section{Conclusion}

It is essential that fundamental human needs such as elimination are satisfied, to maintain health and avoid complications. The findings in our study suggest that the participants are alone in their struggle to have a decent life. The prob- 
lem seems to be neglected by the healthcare system, and it is important that patients' complaints are taken seriously. This study contributes to an extremely sparse body of knowledge about the experience of living with constipation, and more knowledge is needed to be able to develop relevant support programmes.

\section{Acknowledgements}

This study was supported by grants from The Swedish Re- search Council, The Swedish Association of Health Professionals, Ekhaga Foundation, The County Council of Västerbotten, and the Senior Centre of Västerbotten. We would like to acknowledge Ulla Hällgren Graneheim for her valuable contributon.

\section{Conflicts of Interest Disclosure}

No conflict of interest has been declared by the authors.

\section{References}

[1] Wald A, Scarpignato C, Kamm MA, Mueller-Lissner S, Helfrich I, Schuijt C, et al. The burden of constipation on quality of life: results of a multinational survey. Aliment Pharmacol Ther. 2007; 26(2): 227-36. PMID:17593068. http://dx.doi.org/10.1111 /j.1365-2036.2007.03376.x

[2] Walter S, Hallbook O, Gotthard R, Bergmark M, Sjodahl R. A population-based study on bowel habits in a Swedish community: prevalence of faecal incontinence and constipation. Scand J Gastroenterol. 2002; 37(8): 911-6.

[3] Hosia-Randell H, Suominen M, Muurinen S, Pitkala KH. Use of laxatives among older nursing home residents in Helsinki, Finland. Drugs Aging. 2007; 24(2): 147-54.

[4] Harari D, Gurwitz JH, Avorn J, Bohn R, Minaker KL. Bowel habit in relation to age and gender. Findings from the National Health Interview Survey and clinical implications. Arch Intern Med. 1996; 156(3): 315-20.

[5] Mihaylov S, Stark C, McColl E, Steen N, Vanoli A, Rubin G, et al. Stepped treatment of older adults on laxatives. The STOOL trial. Health Technol Assess. 2008; 12(13): iii-iv, ix-139.

[6] Phillips C, Polakoff D, Maue SK, Mauch R. Assessment of constipation management in long-term care patients. Journal of the American Medical Directors Association. 2001; 2(4): 149-54.

[7] McCrea GL, Miaskowski C, Stotts NA, Macera L, Paul SM, Varma MG. Age differences in patients evaluated for constipation: constipation characteristics, symptoms, and bowel and dietary habits. J Wound Ostomy Continence Nurs. 2010; 37(6): 667-76. http: //dx.doi.org/10.1097/WON.0b013e3181f91082

[8] Zutshi M, Hull TL, Bast J, Hammel J. Female bowel function: the real story. Dis Colon Rectum. 2007; 50(3): 351-8. http://dx.doi . org/10.1007/s10350-006-0758-0

[9] Drossman DA, Dumitrascu DL. Rome III: New standard for functional gastrointestinal disorders. J Gastrointestin Liver Dis. 2006; 15(3): 237-41.

[10] Suares NC, Ford AC. Prevalence of, and risk factors for, chronic idiopathic constipation in the community: systematic review and meta-analysis. Am J Gastroenterol. 2011; 106(9): 1582-91.

[11] McCrea GL, Miaskowski C, Stotts NA, Macera L, Varma MG. A review of the literature on gender and age differences in the prevalence and characteristics of constipation in North America. J Pain Symptom Manage. 2009; 37(4): 737-45.

[12] Chiarelli P, Brown W, McElduff P. Constipation in Australian women: prevalence and associated factors. Int Urogynecol J Pelvic Floor Dysfunct. 2000; 11(2): 71-8. PMID:10805262. http://dx .doi.org/10.1007/s001920050073

[13] MacLennan AH, Taylor AW, Wilson DH, Wilson D. The prevalence of pelvic floor disorders and their relationship to gender, age, parity and mode of delivery. BJOG : an international journal of obstetrics and gynaecology. 2000; 107(12): 1460-70.
[14] Kepenekci I, Keskinkilic B, Akinsu F, Cakir P, Elhan AH, Erkek $\mathrm{AB}$, et al. Prevalence of pelvic floor disorders in the female population and the impact of age, mode of delivery, and parity. Dis Colon Rectum. 2011; 54(1): 85-94. http://dx.doi.org/10.1007/DCR $.0 \mathrm{~b} 013 \mathrm{e} 3181 \mathrm{fd} 2356$

[15] Koloski NA, Jones M, Wai R, Gill RS, Byles J, Talley NJ. Impact of persistent constipation on health-related quality of life and mortality in older community-dwelling women. Am J Gastroenterol. 2013; 108(7): 1152-8. http://dx.doi.org/10.1038/ajg. 2013.137

[16] Lämås K, Graneheim UH, Jacobsson C. Experiences of abdominal massage for constipation. J Clin Nurs. 2012; 21(5-6): 757-65. http://dx.doi.org/10.1111/j.1365-2702.2011.03946.x

[17] Koch T, Hudson S. Older people and laxative use: literature review and pilot study report. J Clin Nurs. 2000; 9(4): 516-25.

[18] Friedrichsen M, Erichsen E. The lived experience of constipation in cancer patients in palliative hospital-based home care. International Journal of Palliative Nursing. 2004; 10(7): 321-5. PMID:15365483. http://dx.doi.org/10.12968/ijpn.2004.10.7.14570

[19] Thompson WG, Longstreth GF, Drossman DA, Heaton KW, Irvine EJ, Muller-Lissner SA. Functional bowel disorders and functional abdominal pain. Gut. 1999; 45 Suppl 2: II43-7.

[20] Graneheim UH, Lundman B. Qualitative content analysis in nursing research: concepts, procedures and measures to achieve trustworthiness. Nurse Educ Today. 2004; 24(2): 105-12. http://dx.doi.o $\mathrm{rg} / 10.1016 / \mathrm{j}$. nedt .2003 .10 .001

[21] Krippendorff K. Content analysis: an introduction to its metodology. 2 ed. Thousand Oaks, California: Sage; 2004.

[22] Annells M, Koch T. Faecal impaction: older people's experiences and nursing practice. Br J Community Nurs. 2002; 7(3): 118-26.

[23] Dennison C, Prasad M, Lloyd A, Bhattacharyya SK, Dhawan $\mathrm{R}$, Coyne $\mathrm{K}$. The health-related quality of life and economic burden of constipation. Pharmacoeconomics. 2005; 23(5): 46176. PMID:15896098. http://dx.doi.org/10.2165/0001905 3-200523050-00006

[24] Ronnevig M, Vandvik PO, Bergbom I. Patients' experiences of living with irritable bowel syndrome. J Adv Nurs. 2009; 65(8): 167685. http://dx.doi.org/10.1111/j.1365-2648.2009.05030 . $\mathrm{x}$

[25] Widding-Isaksen L. Den tabubelagte kroppen. Kropp, kjönn og tabuer i dagens omsorgsarbeid (In English; The taboo body. Body, sex and taboos in today's care). Bergen: Universiteteti Bergen; 1994.

[26] Richmond JP, Devlin R. Nurses' knowledge of prevention and management of constipation. Br J Nurs. 2003; 12(10): 600-10.

[27] Sandelowski M. Sample size in qualitative research. Res Nurs Health. 1995; 18(2): 179-83. PMID:7899572. http://dx.doi.o $\mathrm{rg} / 10.1002 /$ nur. 4770180211

[28] Cleary M, Horsfall J, Hayter M. Data collection and sampling in qualitative research: does size matter? J Adv Nurs. 2014; 70(3): 473-5. http://dx.doi.org/10.1111/jan. 12163 